\title{
Allotropic Phase Transformation of Lithium Aluminate in MCFC Electrolyte Plates
}

\author{
Kazuaki NAKAGAWA*, Hideyuki OHZU, Yoshihiro AKASAKA and Norihiro TOMIMATSU
}

Received July 9, 1996 ; Accepted January 6, 1997

\begin{abstract}
Controversy concerning the stable allotropic phase of lithium aluminate in MCFC electrolyte plates has been resumed. To confirm the stability of the $\alpha$ phase under actual MCFC conditions, the allotropic transformation from the $\gamma$ to $\alpha$ phase was investigated. The transformation in electrolyte plates consisting of the $\gamma$ phase was evaluated under various conditions, namely at different temperatures, electrolyte compositions, and atmospheres. A model for this transformation is proposed on the basis of the dissolution-deposition and the particle size difference between the $\alpha$ and $\gamma$ phase. We concluded that a use of the $\alpha$ phase for the electrolyte plates at $650^{\circ} \mathrm{C}$ is rather reasonable than a use of the $\gamma$ phase avoiding $\alpha$ phase inclusion.
\end{abstract}

\section{INTRODUCTION}

Recently, controversy concerning the stable allotropic phase of lithium aluminate in molten carbonate fuel cell (MCFC) electrolyte plates has been resumed. Among the three allotropic phases $(\alpha$, $\beta$, and $\gamma$ ), the $\gamma$ phase has been reported to be the most stable material ${ }^{1)}$. A number of recent studies ${ }^{2-5)}$, however, have shown that the $\gamma$ to $\alpha$ phase transformation took place in electrolyte plates when MCFC is in practical use. These results suggest the following two ideas: (1) the $\alpha$ phase might be more stable than the $\gamma$ phase under the actual conditions of MCFC operations, and (2) the transformation might cause particle growth resulting in a reduction of electrolyte retention. Hatoh et al., reported that the transformation was accelerated by the $\alpha$ phase inclusion in the $\gamma$ phase powder and therefore recommended to reduce the content of the $\alpha$ phase in the initial material in order to inhibit particle growth ${ }^{2)}$.

Materials and Devices Research Labs., Research and Development Center, Toshiba Corporation.

(1, Komukai Toshiba-cho, Saiwai-ku, Kawasaki 210, Japan)

Key Words: Fuel Cell, Lithium Aluminate, Particle Growth, Allotropic transformation
In this study, we attempted to clarify the mechanism of the transfornation from the $\gamma$ to $\alpha$ phase. In an earlier report, we proposed the use of the $\alpha$ phase for electrolyte plates rather than the $\gamma$ phase which has been employed so far ${ }^{6}$. Concerning an electrolyte plate consisting essentially of the $\alpha$ phase, it has been confirmed that the $\alpha$ phase is stable and pore coarsening occurs slowly under the actual conditions of MCFC operation ". Since an increase in the amount of $\alpha$ phase inclusion resulted in the acceleration of the transformation ${ }^{2)}$, we assumed that the transformation was the result of dissolutiondeposition among lithium aluminate particles in the presence of the stable $\alpha$ phase. In order to confirm this assumption, we tested electrolyte plates consisting of the $\gamma$ phase under various conditions. The progress of the transformation was evaluated and conditions accelerating the transformation were identified. A tentative model for the transformation which takes into consideration the difference in particle sizes between the $\gamma$ phase and the $\alpha$ phase is proposed.

\section{EXPERIMENTAL}

\subsection{Matrix fabrication}

Commercially available $\gamma$ phase lithium aluminate powders (Foote: Mineral Company, HSA10 lot. 
9105 and LSA15 lot. 9006) were used as raw materials. The HSA10 powder initially contained $0.91 \%$ of the $\alpha$ phase. Therefore the powders of the same lot were always used in order to avoid differences in $\alpha$ phase inclusion. In the LSA15 powder, no $\alpha$ phase was detected. Electrolyte plate matrices consisting of $70 \mathrm{wt} \%$ HSA 10 and $30 \mathrm{wt} \%$ LSA 15

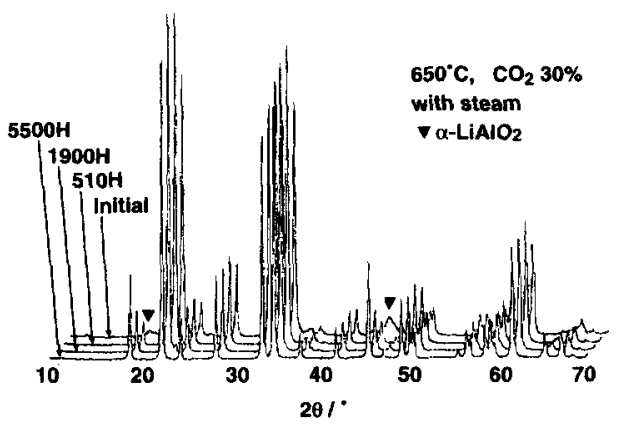

Fig. 1 X-ray diffraction patterns up to $5500 \mathrm{~h}$ of the test $(\mathrm{Li}: \mathrm{K}=62: 38)$.

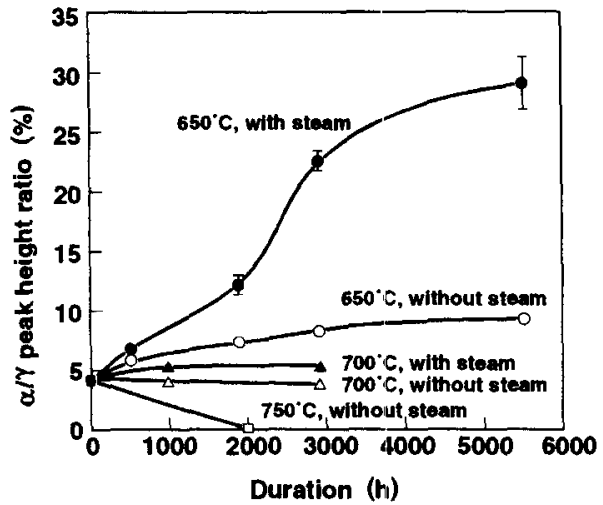

Fig. 2 Change of $\alpha / \gamma$ peak height ratio at various test temperatures $(\mathrm{Li}: \mathrm{K}=62: 38)$.

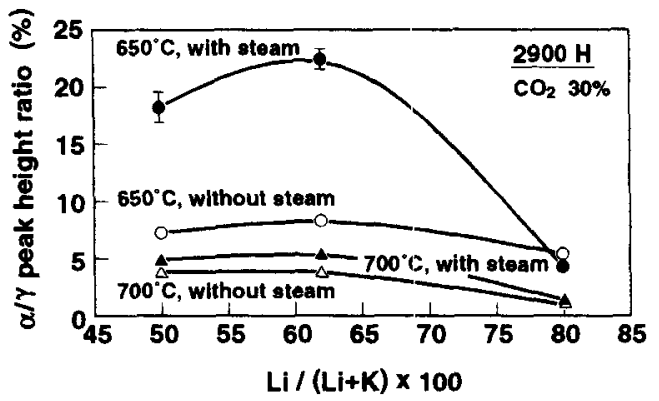

Fig. 3 Relationship between $\alpha / \gamma$ peak height ratio and electrolyte composition. were fabricated using the doctor blade technique

\subsection{Out-of-cell test}

Alkali carbonates in molar ratios of $\mathrm{Li}: \mathrm{K}=80: 20$, 62:38, and 50:50 were impregnated in the sample matrices. The matrices were then heated in a controlled gas environment $\left(\mathrm{CO}_{2} 30 \%\right.$, steamed at $80^{\circ} \mathrm{C}$, balanced by air) in a gold crucible.

After these tests, all the samples were washed by a mixture of acetic acid and acetic anhydride, and then analyzed by an SEM (JSM-5400LV, JEOL) and an X-ray diffractometer (RINT-1200, Rigaku).

\section{RESULTS}

Figure 1 shows the change of X-ray diffraction patterns by the out-of-cell test of up to $5500 \mathrm{~h}$ at $650^{\circ} \mathrm{C}$ in the presence of steam. It is obvious that the small, broad peaks of the $\alpha$ phase at around $19^{\circ}$ and $45^{\circ}$ observed in the initial sample became higher and sharper by the test. This suggests that the small $\alpha$ phase particles which were included in the initial $\gamma$ phase powder increase and become larger during the out-of-cell test. Figure 2 shows the change in the peak height ratio of the $\alpha$ to $\gamma$ phase up to $5500 \mathrm{~h}$. The ratio was calculated using the intensities of the $\alpha$ phase (003) and $\gamma$ phase (101) lines. Similarly to previous reports ${ }^{2,3)}$, the $\alpha$ phase peak ratios rapidly increased at $650^{\circ} \mathrm{C}$, especially in the presence of steam. On the other hand, the $\alpha$ phase peaks completely disappeared after $2000 \mathrm{~h}$ at $750^{\circ} \mathrm{C}$. This result suggests that the $\alpha$ phase is more stable than the $\gamma$ phase below $c a \cdot 700^{\circ} \mathrm{C}$. Figure 3 shows the relationship between the electrolyte composition and $\alpha$ phase peak height ratio. The sample matrix in which the alkali carbonate of higher lithium content was impregnated has a lower $\alpha$ phase peak height ratio than that with lower lithium content. Figure 4 shows the SEM pictures of the sample matrices after $2900 \mathrm{~h}$ of the test. It is obvious that the sample with Li:K=80:20 included larger particles than that with 50:50. Sotouchi et al. reported that the alkali carbonate with a high lithium content caused serious particle growth of lithium aluminate ${ }^{8)}$. 


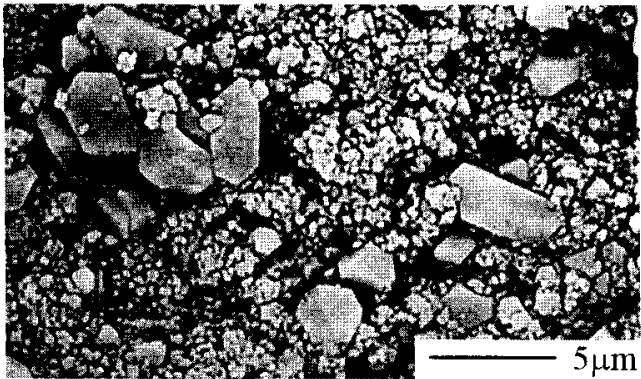

$\mathrm{Li}: \mathrm{K}=80: 20$
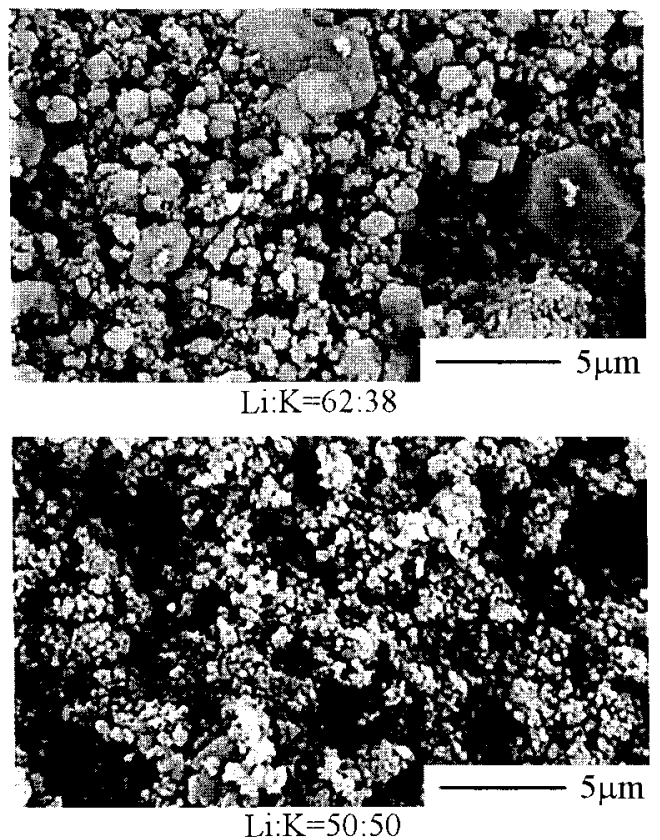

Fig. 4 SEM pictures after $2900 \mathrm{~h}$ of the test on the matrix with three types of alkali carbonate $\left(650^{\circ} \mathrm{C}\right.$, $\mathrm{CO}_{2} 30 \%$, with steam).

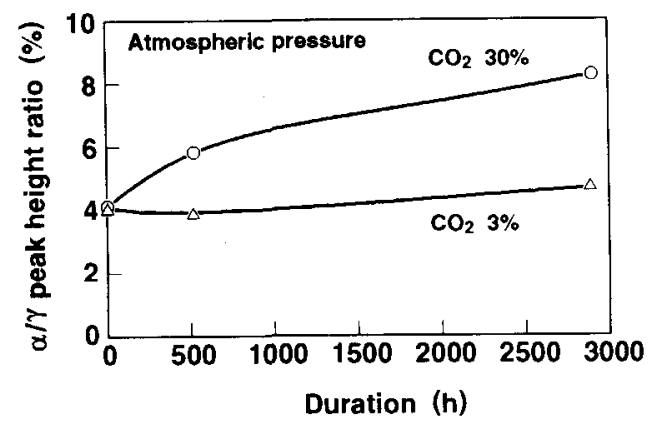

Fig. 5 Effect of $\mathrm{PCO}_{2}$ on $\alpha / \gamma$ peak height ratio change $\left(650^{\circ} \mathrm{C}\right.$, without steam, $\left.\mathrm{Li}: \mathrm{K}=62: 38\right)$.
It is therefore suggested that particle growth may not have direct relation to the transformation. Figure 5 shows the effect of $\mathrm{CO}_{2}$ partial pressure $\left(\mathrm{PCO}_{2}\right)$ on the $\alpha$ phase peak height ratios. It has also been reported that lower $\mathrm{PCO}_{2}$ enhances the solubility of lithium aluminate in alkali carbonate and accelerates particle growth ${ }^{8)}$. In Fig. 5, however, the sample in the gas of higher $\mathrm{PCO}_{2}$ underwent faster transformation than that in the gas of lower $\mathrm{PCO}_{2}$. In the mean while, the rapid particle growth was observed in the latter sample. This result is another example of the fact that the particle growth and transformation have no distinct relationship.

\section{DISCUSSION}

Table 1 summarizes the conditions accelerating the transformation. The results indicate that the transformation does not simply depend on the dissolution-deposition of lithium aluminate, since there is no direct correlation between the transformation and the particle growth. As the first point, the acceleration of the transformation at lower test temperatures can presumably be attributed to the stability of the $\alpha$ phase at lower temperatures in the equilibrium diagram $^{\text {9) }}$, regardless of the presence of alkali carbonate. It was thought that the deposition rate of the $\alpha$ phase on the $\alpha$ phase particles is higher than that of the $\gamma$ phase at $650^{\circ} \mathrm{C}$. This difference results in the dissolution of $\gamma$ phase particles and the consequent development of $\alpha$ phase particles. As the second point, the dependence of the stability of the $\alpha$ phase on the lithium content in earbonate or on $\mathrm{PCO}$.

Table 1 Accelerative conditions for the phase transformation from $\gamma$ to $\alpha$.

\begin{tabular}{|c|}
\hline \multicolumn{2}{|c|}{ Conditions } \\
\hline $\mathrm{CO}_{2}$ Partial Pressure Hower \\
\hline Carbonate Composition Low Li Content \\
\hline Presence of Steam \\
\hline Presence of $\alpha$ phase Inclusion ${ }^{2)}$ \\
\hline
\end{tabular}


should be considered. Since the thermodynamic stability of the $\alpha$ phase essentially depends on the temperature and total pressure of the environment ${ }^{10)}$,

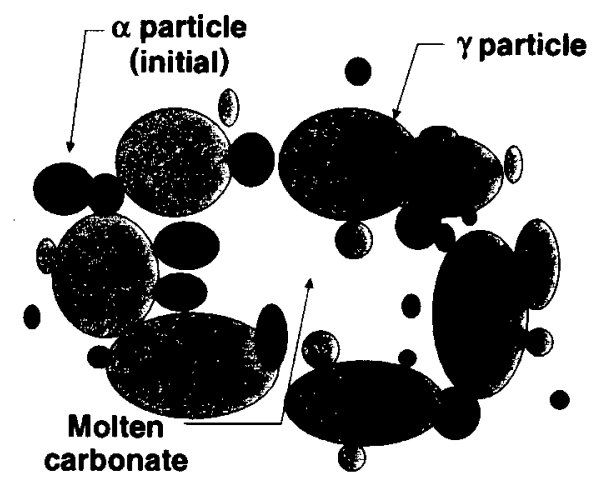

(a) Initial state of the powder.

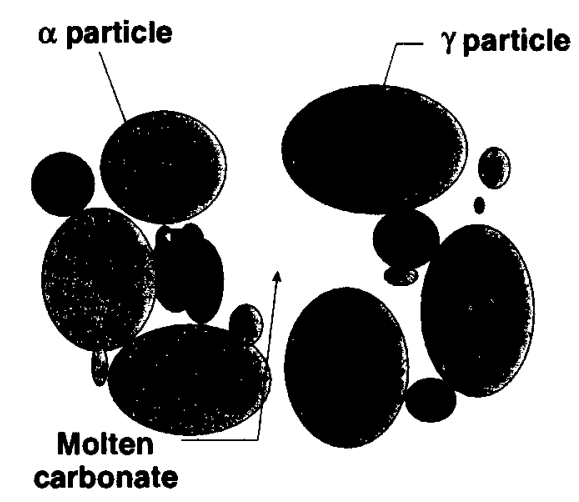

(b) First process of the transformation.

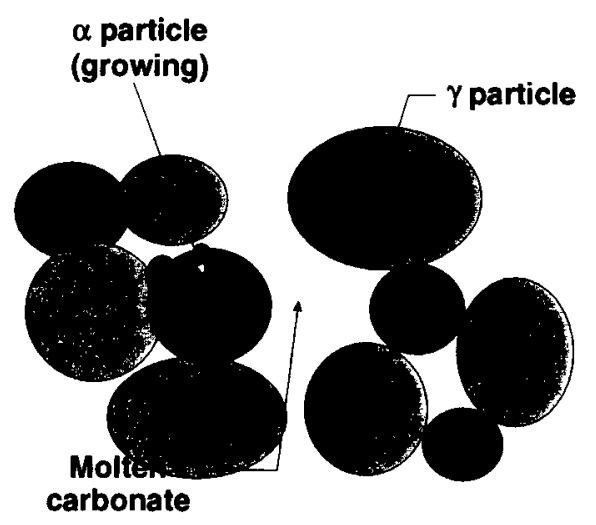

(c) Second process of the transformation.

Fig. 6 A model for the process of the $\gamma$ to $\alpha$ phase transformation at $650^{\circ} \mathrm{C}$. we propose in the following a model which include the effect of the particle size difference between $\alpha$ and $\gamma$ phase particles. According to the previous report ${ }^{2)}$, the $\alpha$ phase inclusion is essential for the transformation. Therefore, this should be considered in the model. We previously reported the difference of the transformation depending on the $\alpha$ phase particle size in the $\alpha-\gamma$ mixture ${ }^{\circ}$. The mixture with smaller $\alpha$ phase particles showed the decrease of the $\alpha$ phase, while the mixture with larger ones showed the increase of the $\alpha$ phase in the same test condition. Saito et al. also reported that the $\gamma$ phase powder tends to contain a large amount of the $\alpha$ phase when the specific surface area of the $\gamma$ phase powder becomes high ${ }^{3)}$. The fact suggests us that such $\alpha$ phase contains rather small particles in comparison with the $\gamma$ phase. According to the theory of liquidphase particle growth ${ }^{11)}$, it is a general phenomenon that larger particles develop consuming smaller ones Under conditions of low $\mathrm{PCO}_{2}$ or high lithium content of the carbonate at $650^{\circ} \mathrm{C}$, part of small particles in the sample matrix dissolves regardless of the phase because of the high solubility of lithium aluminate. Therefore, it was thought that the amount of the $\alpha$ phase which contains small particles decreases and decelerates the transformation. On the other hand, the $\alpha$ phase inclusion does not decrease significantly under conditions of high $\mathrm{PCO}_{2}$ or low lithium content of the carbonate because the solubility of lithium aluminate is low. We believe that the quantitative difference in the presence of the $\alpha$ phase during dissolution-deposition makes the difference in the progress of the transformation.

Figure 6 shows a model of the transformation at the temperatures at which the $\alpha$ phase is stable. Figure 6(a) shows the initial state of the powder. In the first step of the dissolution-deposition of lithium aluminate, the small particles mainly in $\alpha$ phase preferentially dissolve. Hence, the amount of the $\alpha$ phase decreases temporarily ( see Fig. $6(\mathrm{~b}$ ), First process). The extent of the dissolution depends on the solubility. After the process, remaining $\alpha$ phase particles are likely to develop because of its thermo- 
dynamic stability at $650^{\circ} \mathrm{C}$ ( see Fig. $6(\mathrm{c}$ ), Second process). It is thought that the rate of the transformation depends on the amount of remaining $\alpha$ phase particles. Provided there is enough amount of the $\alpha$ phase, the transformation would take place rapidly. The presence of steam has been reported to enhance the dissolution-deposition of lithium aluminate ${ }^{8}$. Thus, it is assumed that steam accelerates the second process without intensive dissolution of $\alpha$ phase particles in the first process.

This model suggests that the allotropic purity and the particle size of the inclusion are significant factors in the process of allotropic transformation. So long as the $\alpha$ phase exists in the sample matrix at $650^{\circ} \mathrm{C}$, however, we believe that the transformation eventually proceeds to yield the complete $\alpha$ phase in infinitely long duration of heating. It is noteworthy, therefore, that the use of $\alpha$ phase powder for the electrolyte plate is more reasonable than the use of $\gamma$ phase powder without the $\alpha$ phase inclusion.

\section{CONCLUSION}

The experimental results indicate that the transformation of the $\gamma$ phase lithium aluminate preferentially proceeds at $650^{\circ} \mathrm{C}$ in the presence of steam. The transformation does not simply depend on the dissolution-deposition. On the basis of these findings, we conclude that the allotropic purity and the particle size of the $\alpha$ phase inclusion are significant factors in the process of allotropic transformation.
The results also indicate that the $\alpha$ phase is stable at the temperature for MCFC operation, viz. $650^{\circ} \mathrm{C}$.

\section{References}

1) P.A.Finn, J.Electrochem.Soc., 127, 236(1980).

2) K.Hatoh, J.Niikura, N.Taniguchi, T.Gamo, and T.Iwaki, Denki Kagaku, 57, 728(1989).

3) T.Saito, Y.Akiyama, Y.Miyake, Y.Ito, M.Nishioka, and S.Murakami, Denki.Kagaku, 59, 712(1991).

4) T.Nishimura, J.Hosokawa, Y.Fujita, and H.Urushibata, The 35th Battery Symposium in Japan, Abstract No.1D14 (1994).

5) K.Tanimoto, M.Yanagida, T.Kojima, Y.Tamiya, T. Asai, and Y.Miyazaki, Proceedings of the 3rd FCDIC Fuel Cell Symposium, B2-6 (1996).

6) N.Tomimatsu, H.Ohzu, Y.Akasaka, and K.Nakagawa, Electrochem.Soc. Fall Meeting Abstract No.86(1995)

7) K.Nakagawa, H.Ohzu, Y.Akasaka, and N.Tomimatsu, Denki Kagaku, 64, 478(1996).

8) H.Sotouchi, Y.Watanabe, T.Kobayashi, and M.Murai, J.Electrochem.Soc.,139, 1127(1992).

9) H.C.Maru, L.Paetsch and A.Pigeaud, Proceedings of the Symposium on Molten Carbonate Fuel Cell Technology, 20(1984).

10) Harlan J. Byker, Isaac Eliezer, Naomi Eliezer, and Reed A. Howald, J.Phys.Chem., 83, 2349(1979).

11) G.W.Greenwood, Acta Metallurgica, 4,243(1956). 